I N S T I T U T O

$\mathrm{DE}$

M E D I C I N A

T R O P I C A L

$\mathrm{DE}$

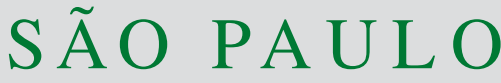

JOURNAL OF THE SÃO PAULO INSTITUTE OF TROPICAL MEDICINE

${ }^{1}$ Universidade Estadual Paulista, Faculdade de Medicina Veterinária e Zootecnia, Departamento de Produção Animal e Medicina Veterinária Preventiva, Botucatu, São Paulo, Brazil

2Universidade Estadual Paulista, Instituto de Biociências, Departamento de Microbiologia, Botucatu, São Paulo, Brazil

${ }^{3}$ Universidade Estadual Paulista, Faculdade de Medicina, Botucatu, São Paulo, Brazil

${ }^{4}$ Universidade de Feira de Santana, Departamento de Ciências Biológicas, Feira de Santana, Bahia, Brazil

Correspondence to: Márcio Garcia Ribeiro Universidade Estadual Paulista, Faculdade de Medicina Veterinária e Zootecnia, Departamento de Produção Animal e Medicina Veterinária Preventiva, Laboratório de Microbiologia/Doenças Infecciosas dos Animais, CEP 18618-681, Botucatu, SP, Brazil

Tel:. +55 14 3880-2102

E-mail: marcio.ribeiro@unesp.br

Received: 26 January 2021

Accepted: 22 May 2021

\section{Safety issues of raw milk: evaluation of bacteriological and physicochemical characteristics of human milk from a bank in a teaching hospital, focusing on Staphylococcus species}

\author{
Tatiana Salerno ${ }^{\circledR}$, Amanda Keller Siqueira ${ }^{(1)}$, José Paes de Almeida \\ Nogueira Pinto ${ }^{(1}$, Maria de Lourdes Ribeiro de Souza da Cunha ${ }^{\circledR}$, Patrícia \\ Kelly Silvestre ${ }^{3}$, Larissa Anuska Zeni Condas ${ }^{(1)}$, Gustavo Henrique Batista \\ Lara $^{1}$, Juliano Gonçalves Pereira ${ }^{\circledR}$, Aristeu Vieira da Silva ${ }^{\circledR}$, Fernando \\ José Paganini Listoni ${ }^{\circledR}$, Lorrayne de Souza Araújo Martins ${ }^{(1)}$, Rodrigo \\ Garcia Motta $^{(1)}$, Márcio Garcia Ribeiro 1
}

\section{ABSTRACT}

Many infants are nurtured with milk supplied by human banks, whose bacteriological and physical-chemical profiles are a major issue. We investigated the bacteriological and physical-chemical characteristics, as well as genotypic and phenotypic and profiles of Staphylococcus species isolated from 240 samples of breast milk from a bank in a teaching hospital. Dornic acidity of milk revealed that $95.4 \%$ (229/240) had acceptable limits $\left(<8.0^{\circ} \mathrm{D}\right)$. Caloric intake showed a wide variation in cream content $(4 \%)$, fat $(4 \%)$ and energy values (559.81 Kcal/L). Staphylococcus (105/186 or 56.5\%) and Enterobacter (25/186 or $13.4 \%$ ) were the most prevalent genera, although other microorganisms were identified, including Klebsiella pneumoniae and Pseudomonas aeruginosa. Amoxicillin/clavulanic acid $(125 / 157$ or $79.6 \%)$, vancomycin $(115 / 157$ or $73.2 \%)$, and cephalexin $(112 / 157$ or $71.3 \%$ ) were the most effective antimicrobials. High resistance rates of isolates were found to penicillin $\mathrm{G}$ (141/157 or $89.8 \%$ ), ampicillin (135/157 or $86 \%$ ), and oxacillin (118/157 or $75.2 \%$ ). Multidrug resistance to $\geq 3$ antimicrobials occurred in $66.2 \%(123 / 186)$ of the isolates. Residues of microbial multiplication inhibitory substances were found in 85\% (204/240) of samples. Among the coagulase-positive-CPS and negative-CoNS staphylococci, the mecA gene was detected in 53.3\% (8/15) and 75\% (30/40), respectively. Genes sea, seb and sec were detected in $20 \%$ (3/15) of CPS, while $t s s t-1$ was detected in $13.34 \%(2 / 15)$. In addition, $13.3 \%(2 / 15)$ of $S$. aureus were toxin-producers. Genes sea, seb and sec were detected in $90 \%$ (36/40), 5\% (2/40) and 15\% (6/40) CoNS, respectively. Enterotoxin production was identified in $5 \%(2 / 40)$ of CoNS. The identification of multidrug-resistant bacteria, staphylococci species toxin-producers harboring methicillin-resistance genes, and residues of microbial multiplication inhibitory substances reinforce the need for a continuous vigilance of milk quality offered to infant consumption by human banks.

KEYWORDS: Neonatal milk. Human milk banks. Breastfeeding. Multidrug-resistant bacteria. Staphylococcal toxins.

\section{INTRODUCTION}

Human breast milk is recognized as the primary source of nutrition and of organic defense for newborns. Breastfeeding is recommended at least during the first six months of life and should be encouraged until two years of age ${ }^{1}$. 
Breastfeeding is also well-known as a means of strengthening the bond between mother and child, and it is able to influence psychological and emotional conditions ${ }^{2}$.

Human milk banks are usually located in maternal or pediatric hospitals. These banks are responsible for the promotion and encouragement of breastfeeding and also for collection, processing and quality control of colostrum, transitional and mature milk, and distribution, upon prescription by the attendant physicians ${ }^{3,4}$. They guarantee the supply of milk as the first food option for preterm infants, contributing to the prevention of neonatal diseases and reducing infant's mortality, especially of those who did not have access to their mothers' milk $^{5}$.

The quality of milk supplied by the human milk banks has been investigated worldwide, particularly regarding the microbial profile, the resistance of microorganisms to antimicrobials used in medical practice, and the pasteurization procedure to improve the collection and storage of milk offered in human banks ${ }^{2-4,6-8}$.

The microbiological profile of human milk is a major issue, as breast milk may contain commensal bacteria that are important to establish the enteric microbiota of neonates in the first days of life, e.g., staphylococci, streptococci, corynebacterium species and lactic acid producing bacteria 9 . Nonetheless, these bacteria may act as a reservoir of antibiotic resistant genes, which are similar to those reported in pathogenic bacteria ${ }^{10}$.

Staphylococci are well-known gram-positive bacteria that can be found as an inhabitant of the skin, mucosa (urogenital, upper respiratory tract), and conjunctive microbiota of humans and animals, and that may also be related to different clinical infections ${ }^{11}$. Studies that investigated the microbiota of human breast milk of healthy mothers and bank donors have reported a predominance of Staphylococcus species among isolated bacteria ${ }^{3,10,12}$.

On a global level, the multidrug-resistant bacteria originated from humans and domestic animals are an emergent public health concern ${ }^{13}$. A set of mechanisms and genes related to antimicrobial resistance have been described in different bacteria. Particularly among staphylococci strains, including Staphylococcus aureus and coagulase-negative staphylococci (CoNS), the mecA gene has been used to predict methicillin resistance $^{14}$ and provide initial support in therapeutic decision-making ${ }^{15}$.

Antimicrobials have been indicated in the treatment of puerperal mastitis or used in pre- and postpartum prophylaxis as well as in caesarean sections, belonging mainly to the group of first and second-generation penicillins and cephalosporins. These drugs are considered safe during lactation because of the small number of antibiotic-derived residues excreted in milk due to the high binding rate with maternal plasma proteins. The presence of chemical residues, especially those from antimicrobials in breastfeeding milk has been a concern for humans ${ }^{16}$, reinforcing that a continuous vigilance of microbiological and physicochemical conditions of milk offered to infants is necessary in human banks ${ }^{4}$. In this scenario, we investigated the bacteriological quality, physical-chemical characteristics, the presence of residues of microorganism-inhibiting substances in human breast milk, as well as toxin-producers and multidrug-resistance staphylococci strains in a milk bank of a teaching hospital.

\section{MATERIALS AND METHODS}

\section{Ethics statement}

This study was approved by the Ethics Committee, Veterinary Medicine and Animal Sciences, UNESP, Botucatu, Sao Paulo, Brazil (protocol No 037/11).

\section{Breast milk samples}

Two hundred and forty samples of raw human milk were conveniently sampled ${ }^{4,5}$ from the routine of microbiological and physicochemical analysis of raw breast milk weekly sent to the Food Inspection Laboratory, at the School of Veterinary Medicine and Animal Sciences, UNESP/ Botucatu, Sao Paulo, Brazil, from a human milk bank in a Teaching Hospital located on the center of Sao Paulo State, Brazil. The milk was collected between 8-15 days after delivery, avoiding the colostrum period. Samples were subjected to microbiological and physicochemical tests and then, pasteurized and stored at temperatures between $-21^{\circ} \mathrm{C}$ and $-10^{\circ} \mathrm{C}$. The human milk bank followed the guidelines of the Brazilian Human Milk Banks Network ${ }^{17}$. The identity of donors was maintained anonymous.

\section{Dornic acidity and crematocrit analyses}

Dornic acidity was determined as previously described using $4 \mathrm{~mL}$ of breast milk. Values accepted by the Brazilian human milk bank network comprise the range of 1-8 ${ }^{\circ} \mathrm{D}$. The crematocrit of milk samples, used to evaluate the cream content, total fat and energy value was carried out based on standardized method ${ }^{18}$, using the following calculation: cream content: cream column (mm) x $100 \div$ total column $(\mathrm{mm})=$ cream $\%$; Fat content: $($ cream $\%-0.59) \div 1.46=$ fat $\%$; Total energy content: $($ cream $\%$ x $66.8+290)=\mathrm{Kcal} / \mathrm{L}$. 


\section{Bacterial identification}

Milk samples were plated on 5\% sheep blood agar and MacConkey agar, maintained under aerobic conditions at $37^{\circ} \mathrm{C}$, for $72 \mathrm{~h}$. The isolates were identified according to conventional phenotypic features. The suggestive colonies of staphylococci were stained by the gram method and isolates presenting with grouped gram-positive cocci were subjected to coagulase tests to identify coagulase-positive (CPS) and coagulase-negative (CoNS) isolates ${ }^{11}$.

Fermentation tests of maltose, trehalose and mannitol sugars, resistance to polymyxin B (300 IU), and acetoin production were carried out to identify $S$. aureus species in addition to other $\mathrm{CPS}^{11}$. The differentiation among CoNS species was performed using a modified method described previously ${ }^{19}$. All isolates were stored in tubes containing nutrient broth and glycerol (5\%) and they were kept at $-20{ }^{\circ} \mathrm{C}$.

\section{In vitro antimicrobial susceptibility pattern}

Microorganisms were subjected to in vitro antimicrobial susceptibility test by the standard disk diffusion method ${ }^{20}$, using 11 antimicrobials from six different classes, as follow: 1) penicillin and derivatives (amoxicillin/ clavulanic acid $10 / 20 \mu \mathrm{g}$, ampicillin $10 \mu \mathrm{g}$, oxacillin $5 \mu \mathrm{g}$, penicillin $10 \mathrm{IU}), 2$ ) cephalosporins (cephalexin $30 \mu \mathrm{g}$, cefoxitin $30 \mu \mathrm{g}$ ), 3) macrolides (erythromycin $15 \mu \mathrm{g}$ ), 4) aminoglycosides (gentamicin $10 \mu \mathrm{g}$, neomycin $30 \mu \mathrm{g}$ ), 5) sulphonamides (trimethoprim/sulfamethoxazole $25 \mu \mathrm{g}$ ), and 6) glycopeptides (vancomycin $30 \mu \mathrm{g}$ ). Multidrugresistant bacteria were considered when there was simultaneous resistance to three or more classes of the tested antimicrobials ${ }^{21}$.

Phenotypic identification of methicillin-resistant Staphylococcus (MRS) and the minimum inhibitory concentration (MIC)

The susceptibility testing using oxacillin $(1 \mu \mathrm{g})$ and cefoxitin $(30 \mu \mathrm{g})$ discs was performed by the agar diffusion technique to MRS. All CPS and 40 CoNS randomly selected were submitted to the phenotypic investigation of MRS. MIC was determined also by the agar diffusion technique, using oxacillin strips $(0.016-0.256 \mu \mathrm{g} / \mu \mathrm{g})^{20}$.

\section{Identification of microbial multiplication inhibitors in} milk

The presence of microbial multiplication inhibitors in breast milk was evaluated using a commercial kit (Delvotest ${ }^{\mathrm{TM}}$, DSM Food Specialties, Delft, The Netherlands) ${ }^{22}$ according to the manufacturer's standards. This qualitative test is based on the change of colors and can identify $>10 \mathrm{ng} / \mathrm{mL}$ of the tested classes/antimicrobials: beta-lactams (penicillin-G, ampicillin, amoxicillin, cefacetrile, cefalexin, cefalonium, cefoperazone, cefapirin, ceftiofur, cloxacillin, dicloxacillin, oxacillin, nafcillin), sulphonamides (sulfadiazine, sulfadimethoxine, sulfamethazine, sulfathiazole), tetracyclines (tetracycline, oxytetracycline, chlortetracycline), macrolides (erythromycin, tylosin, spiramycin), aminoglycosides (gentamycin, neomycin, dihydrostreptomycin, kanamycin), lincosamides (lincomycin), amphenicols (chloramphenicol), and dihydropyrimidine (trimethoprim).

\section{Genotypic detection of resistance and toxin genes}

DNA extraction was performed from CPS and CoNS using a commercial kit (Illustra $^{\mathrm{TM}}$, Blood GenomicPrep MiniSpin, G.E. Healthcare Life Sciences, USA), according to the manufacturer's instructions. DNA samples were stored at $-20{ }^{\circ} \mathrm{C}$. The detection of methicillin-resistant isolates (MRS) was based on the polymerase chain reaction (PCR) results ${ }^{23}$. S. aureus ATCC 33591 was used as a positive control (MRSA) and S. aureus ATCC 25923 as a negative control (susceptible strain).

Amplifications were carried out as described previously ${ }^{19}$ to investigate the genes encoding the enterotoxins SEA, SEB, SEC and SED, and the toxic shock syndrome toxin 1 (TSST-1). S. aureus ATCC 13565, ATCC 14458, ATCC 19095, ATCC 23235 and ATCC 51650 were used as positive controls for sea, seb, sec, sed, and tsst-1 genes, respectively. Sterile water was used as a negative control.

\section{Phenotypic detection of toxin production}

S. aureus, other CPS and CoNS-positive for toxinencoding genes were subjected to phenotypic tests to evaluate gene expression. The production of enterotoxins A, B, C, $\mathrm{D}$ and toxic shock syndrome 1 toxin (TSST-1) in S. aureus strains was investigated using the cellophane-over-agar ${ }^{24}$.

The sac culture method was used for CoNS and CPS (except S. aureus) to produce large amounts of SEA, SEB, SEC, SED and TSST-1 toxins. Later, the detection of the extracellular product was performed using a rapid reversed passive latex agglutination (RPLA) ${ }^{25}$ test. Subsequently, the detection of enterotoxins A, B, C, and D was based on the SET-RPLA toxin commercial kit (Oxoid ${ }^{\mathrm{TM}}$, Waltham, USA) results and TSST- 1 by the TSST-RPLA Toxin Detection kit (Oxoid ${ }^{\mathrm{TM}}$, Waltham, USA) following the manufacturer's instructions. 


\section{Statistical analysis}

The $95 \%$ confidence interval (CI) for both positive and negative samples was calculated based on the absolute and relative frequencies of isolation of microorganisms from milk samples. The association between the microbiological profile, the acidity values and the presence of microbial multiplication inhibitors were compared with each other using the appropriate tests in each case, i.e., Chi-square $\left(\chi^{2}\right)$, Fisher's exact and Williams $\mathrm{G}$ tests. The phenotypic and genotypic comparison between methicillin and/or oxacillin resistant CPS and CoNS versus the detection of toxin encoding genes was analysed using the Fisher exact test or the $\chi^{2}$, with a level of significance set at 0.05 .

\section{RESULTS}

\section{Acidity and crematocrit}

Data on titrated Dornic acidity $\left({ }^{\circ} \mathrm{D}\right)$ ranged from $2.5^{\circ} \mathrm{D}$ to $12.5^{\circ} \mathrm{D}$, as follow: $2.5^{\circ} \mathrm{D}(107 / 240$ or $44.6 \%), 5.0^{\circ} \mathrm{D}$ (102/240 or $42.5 \%), 7.5{ }^{\circ} \mathrm{D}(20 / 240$ or $8.3 \%), 10.0^{\circ} \mathrm{D}$ (6/240 or $2.5 \%), 12.5{ }^{\circ} \mathrm{D}(5 / 240$ or $2.1 \%)$. Of these, $95.4 \%$ $(229 / 240)$ of milk samples had titratable acidity $<8.0^{\circ} \mathrm{D}$ and only $4.6 \%(11 / 240)$ had titratable acidity $>8.0^{\circ} \mathrm{D}$.

\section{Cream, fat, and energy content}

The average (minimum and maximum value) of cream, fat and energy content among the 240 milk samples was $4.0 \%(1.54-11.3 \%), 2.4 \%(0.65-7.3 \%)$ and $55.8 \mathrm{Kcal} / \mathrm{L}$ (392.8-1,044.19 Kcal/L), respectively.

\section{Identification of microorganisms}

One hundred and eighty-sixth bacteria and yeast were isolated among the 240 samples of human breast milk. Staphylococcus (105/186 or 56.5\%), Enterobacter (25/186 or $13.4 \%$ ), and Bacillus (22/186 or $11.8 \%$ ) were the most frequent genera isolated (Table 1). Other microorganisms were less frequently identified, e.g., Klebsiella pneumoniae (03/186 or $1.6 \%)$, Pseudomonas aeruginosa (03/186 or $1.6 \%)$, Hafnia alvei (02/186 or 1.1), and Klebsiella oxytoca $(1 / 186$ or $0.5 \%)$. Enterobacteria, i.e., Enterobacter sp., Klebsiella pneumoniae, Hafnia alvei and Klebsiella oxytoca, represented $16.6 \%$ of the isolates.

Among 105 staphylococci isolates, 14.3\% (15/105) were classified as CPS and $85.7 \%$ (90/105) as CoNS. Only $4.7 \%(5 / 105)$ were identified as $S$. aureus. Among CoNS, S. epidermidis was the most frequent species $(75 / 105$ or $71.4 \%$ ) (Table 2).
Table 1 - Microorganisms isolated from 240 samples of human milk in a Teaching Hospital from Sao Paulo State, Brazil.

\begin{tabular}{lc}
\hline Microorganisms & $\begin{array}{c}\text { Number of isolates / total of } \\
\text { isolates (\%) }\end{array}$ \\
\hline Staphylococcus sp. & $105 / 186(56.5)$ \\
Enterobacter sp. & $25 / 186(13.4)$ \\
Bacillus sp. & $22 / 186(11.8)$ \\
Streptococcus sp. & $09 / 186(4.8)$ \\
Acinetobacter sp. & $08 / 186(4.3)$ \\
Yeast & $07 / 186(3.8)$ \\
Klebsiella pneumoniae & $03 / 186(1.6)$ \\
Pseudomonas aeruginosa & $03 / 186(1.6)$ \\
Hafnia alvei & $02 / 186(1.1)$ \\
Klebsiella oxytoca & $01 / 186(0.5)$ \\
Micrococcus sp. & $01 / 186(0.5)$ \\
\hline Total & $186 / 186(100)$ \\
\hline
\end{tabular}

Table 2 - Species characterization of coagulase-positive staphylococci (CPS) and coagulase-negative staphylococci (CoNS) in 105 staphylococcal isolates obtained from 240 milk samples in a Teaching Hospital from Sao Paulo State, Brazil.

\begin{tabular}{lc}
\hline Species & $\begin{array}{c}\text { Number/ total of } \\
\text { Staphylococci isolates (\%) }\end{array}$ \\
\hline CPS & \\
\hline Staphylococcus spp. & $10 / 105(9.5)$ \\
S. aureus & $05 / 105(4.8)$ \\
Subtotal & $15 / 105(14.3)$ \\
\hline CoNS & \\
\hline S. epidermidis & $75 / 105(71.4)$ \\
S. saprophyticus & $06 / 105(5.7)$ \\
Staphylococcus spp. & $04 / 105(3.8)$ \\
S. simulans & $02 / 105(1.9)$ \\
S. xylosus & $02 / 105(1.9)$ \\
S. lugdunensis & $01 / 105(0.9)$ \\
Subtotal & $90 / 105(85.7)$ \\
\hline Total & $105 / 105(100)$ \\
\hline
\end{tabular}

No isolation of microorganisms was observed in $40 \%$ (96/240) of milk samples.

In vitro antimicrobial susceptibility test

Amoxicillin/clavulanic acid $(125 / 157=79.6 \%)$, vancomycin $(115 / 157=73.2 \%)$ and cephalexin $(112 / 157=71.3 \%)$ were the most effective antimicrobial agents against isolates (Table 3). High resistance rates were found to penicillin $\mathrm{G}$ (141/157 or $89.8 \%)$, ampicillin $(135 / 157$ or $86 \%)$ and oxacillin $(118 / 157$ or $75.2 \%)$ 
(Table 3). Particularly to staphylococci isolates, vancomycin (105/105 or $100 \%)$, amoxicillin/clavulanic acid (100/105 or $95.2 \%$ ), and cephalexin $(98 / 105$ or $93.3 \%$ ) were the most effective antimicrobials. Simultaneous resistance to three or more classes of antimicrobials tested (multidrug-resistance) was found in 66.2\% (123/186) of all bacterial isolates.

All 15 CPS isolates were subjected to the phenotypic investigation of MRS. From these, 33.3\% (5/15) were resistant to oxacillin and/or cefoxitin, whereas $93.3 \%$ $(14 / 15)$ were resistant to penicillin. Only one (1/15 or 6.7\%) Staphylococcus strain presented with a simultaneous resistance to oxacillin, penicillin and oxacillin (discs and strip). Out of 40 (40/90 or $44.4 \%$ ) CoNS subjected to the phenotypic investigation of MRS, 67.5\% (27/40) showed resistance to oxacillin and/or cefoxitin, while 95\% (38/40) revealed resistance to penicillin. Using the oxacillin strip, the resistance of isolates was observed in $45 \%$ (18/40) of CoNS (Table 4).

When comparing the occurrence of methicillin resistance between CPS and CoNS isolates using phenotypic methods (AST and MIC), a statistically significant difference $(\mathrm{p}<0.05)$ was found only for the MIC test with oxacillin

Table 3 - In vitro antimicrobial susceptibility pattern of bacteria isolated from 240 samples of human milk in a Teaching Hospital from Sao Paulo State, Brazil.

\begin{tabular}{|c|c|c|c|c|}
\hline \multirow{2}{*}{ Classes } & \multirow{2}{*}{ Antimicrobials } & Sensitive & Intermediate & Resistant \\
\hline & & \multicolumn{3}{|c|}{ Number /total (\%) } \\
\hline \multirow{2}{*}{ Aminoglycosides } & Gentamicin & $96 / 157(61.2)$ & 9/157 (5.7) & $52 / 157(33.1)$ \\
\hline & Neomycin & $56 / 157(35.7)$ & $61 / 157(38.8)$ & $40 / 157(25.5)$ \\
\hline \multirow{2}{*}{ Cephalosporins } & Cefoxitin & $66 / 157(42)$ & $5 / 157(3.2)$ & $86 / 157(54.8)$ \\
\hline & Cephalexin & 112/157 (71.3) & 6/157 (3.8) & $39 / 157(24.9)$ \\
\hline Glycopeptides & Vancomycin & $115 / 157(73.2)$ & $0 / 157(0)$ & $42 / 157(26.8)$ \\
\hline Macrolides & Erytromycin & $20 / 157(12.7)$ & $43 / 157(27.4)$ & $94 / 157(59.9)$ \\
\hline \multirow{4}{*}{ Penicillin $\mathrm{G}$ and derivatives } & Amoxacillin/clavulanic acid & $125 / 157(79.6)$ & $5 / 157(3.2)$ & $27 / 157(17.2)$ \\
\hline & Ampicillin & $21 / 157(13.4)$ & $1 / 157(0.6)$ & $135 / 157(86)$ \\
\hline & Oxacillin & $36 / 157(22.9)$ & $3 / 157(1.9)$ & $118 / 157(75.2)$ \\
\hline & Penicillin G & $15 / 157(9.6)$ & $1 / 157(0.6)$ & $141 / 157(89.8)$ \\
\hline Sulfonamides & Trimethoprim/sulfamethoxazole & $103 / 157(65.6)$ & $6 / 157(3.8)$ & $48 / 157(30.6)$ \\
\hline
\end{tabular}

Table 4 - Phenotypic and genotypic identification of methicillin-resistant Staphylococcus (MRS) isolated from samples of human milk in a Teaching Hospital from Sao Paulo State, Brazil.

\begin{tabular}{|c|c|c|c|c|c|}
\hline & AST Cefoxitin & AST Oxacillin & AST Penicillin & MIC Oxacillin & PCR mecA \\
\hline & $\mathrm{n} / \mathrm{T}(\%)$ & $\mathrm{n} / \mathrm{T}(\%)$ & $\mathrm{n} / \mathrm{T}(\%)$ & $\mathrm{n} / \mathrm{T}(\%)$ & $\mathrm{n} / \mathrm{T}(\%)$ \\
\hline \multicolumn{6}{|l|}{ CPS } \\
\hline S. aureus & $01 / 15(6.67)$ & 02/15 (13.33) & 05/15 (33.33) & $0 / 15(0)$ & $02 / 15(13.33)$ \\
\hline Staphylococcus spp. & 02/15 (13.33) & $03 / 15(20)$ & $09 / 15(60)$ & $1 / 15(6.67)$ & $06 / 15(40)$ \\
\hline Total & $03 / 15(20)$ & 05/15 (33.33) & 14/15 (93.33) & $1 / 15(6.67)$ & 08/15 (53.33) \\
\hline \multicolumn{6}{|l|}{ CoNS } \\
\hline S. epidermidis & $13 / 40(32.50)$ & $16 / 40(40)$ & $25 / 40(62.50)$ & $12 / 40(30)$ & $22 / 40(55)$ \\
\hline S. lugdunensis & $0 / 40(0)$ & $0 / 40(0)$ & $01 / 40(2.50)$ & $01 / 40(2.50)$ & $0 / 40(0)$ \\
\hline S. saprophyticus & $03 / 40(7.50)$ & $04 / 40(10)$ & $05 / 40(12.50)$ & 02/40 (5) & $03 / 40(7.50)$ \\
\hline S. simulans & $01 / 40(2.50)$ & $01 / 40(2.50)$ & $02 / 40(5)$ & $01 / 40(2.50)$ & $02 / 40(5)$ \\
\hline S. xylosus & $01 / 40(2.50)$ & $01 / 40(2.50)$ & 02/40 (5) & 02/40 (5) & $01 / 40(2.50)$ \\
\hline Staphylococcus spp. & $03 / 40(7.50)$ & $02 / 40(5)$ & $03 / 40(7.50)$ & $0 / 40(0)$ & $02 / 40(5)$ \\
\hline Total & $21 / 40(52.50)$ & $24 / 40(60)$ & $38 / 40$ (95) & $18 / 40(45)$ & $30 / 40(75)$ \\
\hline
\end{tabular}

AST = antimicrobial susceptibility testing by the disk diffusion method; MIC = minimal inhibitory concentration; PCR = polymerase chain reaction; $\operatorname{mec} A$ = gene encoding methicillin resistance; $n=$ number of isolates; $T=$ total of isolates; CPS = Coagulase-positive staphylococci; CoNS = Coagulase-negative staphylococci. 
$(p=0.0268)$. There was no significant difference in bacterial resistance between CPS and CoNS isolates to cefoxitin $(p=0.774)$, oxacillin $(p=0.1529)$ and penicillin $(p=0.6234)$.

Microbial multiplication inhibitors in milk

Among all samples of human milk, 85\% (204/240) revealed the presence of microbial multiplication inhibiting substances.

Genotypic detection of methicillin resistance gene (mecA)

The mecA gene was detected in $53.3 \%$ (8/15) of CPS. Among CPS strains, in $46.7 \%$ (7/15) there was no gene detection. Of these, $28.7 \%$ (2/7) of CPS-negative for mecA gene showed resistance to oxacillin and/or cefoxitin, and also to penicillin.

From CoNS, the gene mecA was detected in 75\% (30/40) isolates, being 55\% (22/40) S. epidermidis. In 25\% (10/40) of CoNS, no mecA gene was detected, although $20 \%(2 / 10)$ were resistant to oxacillin in the MIC test. There was no significant difference ( $p=0.1122)$ between CPS and CoNS isolates regarding the detection of mecA gene.

\section{Molecular identification of the genes and staphylococcal toxins}

The sea, seb and sec genes were detected in 20\% (3/15) of the CPS isolates. The tsst-1 gene was identified in $13.3 \%$ $(2 / 15)$. The simultaneous occurrence of two or more of these genes was found in $26.7 \%$ (4/15) of CPS isolates. Of the 15 CPS isolates, $13.3 \%$ (2/15) S. aureus were phenotypic toxin-producers. From these, 6.7\% (1/15) produced SEA and TSST-1, and another isolate SEA and SEC, although also harbouring the seb gene. The sea gene was detected in 90\% (36/40) of CoNS. In only 5\% (2/40) of these isolates, the $s e b$ and $s e c$ genes were detected. Enterotoxin D and TSST-1 toxin-encoding genes were not identified among CoNS isolates (Table 5).

The occurrence of two or more genes was found in $17.5 \%$ (7/40) of CoNS. The association of sea and sec genes occurred in $12.5 \%$ (5/40) of CoNS isolates. The sea and seb genes were identified in 5\% (2/40). Enterotoxin production was detected in 5\% (2/40). From these, S. saprophyticus was a SEA toxin-producer, while Staphylococcus spp. of SEB toxin-producer (Table 6).

Comparing CPS and CoNS isolates for the presence of encoding genes for staphylococcal toxins, the statistically significant difference $(p<0.0001)$ was found only for the sea gene.

\section{DISCUSSION}

In this study, weidentified a complexity of microorganisms, multidrug-resistant bacteria, and staphylococci species toxin-producers harboring methicillin-resistance genes, as well as the presence of microbial multiplication inhibiting substances, among human breast milk samples intended for newborns' consumption in a teaching hospital, in Brazil. The physicochemical and microbiological characteristics of the human milk distributed to human milk banks are

Table 5 - Toxin genes of staphylococci identified in human milk from a bank in a Teaching Hospital from Sao Paulo State, Brazil.

\begin{tabular}{|c|c|c|c|c|c|}
\hline \multirow{2}{*}{ Genes } & sea & seb & $\mathrm{sec}$ & sed & tsst- 1 \\
\hline & $\mathrm{n} / \mathrm{T}(\%)$ & $\mathrm{n} / \mathrm{T}(\%)$ & $\mathrm{n} / \mathrm{T}(\%)$ & $\mathrm{n} / \mathrm{T}(\%)$ & $\mathrm{n} / \mathrm{T}(\%)$ \\
\hline \multicolumn{6}{|l|}{ CPS } \\
\hline S. aureus & $2 / 15(13.3)$ & $1 / 15(6.7)$ & 2/15 (13.3) & $0 / 15(0)$ & $1 / 15(6.7)$ \\
\hline Staphylococcus spp. & $1 / 15(6.7)$ & 2/15 (13.3) & $1 / 15(6.7)$ & $0 / 15(0)$ & $1 / 15(6.7)$ \\
\hline Total & $3 / 15(20)$ & $3 / 15(20)$ & $3 / 15(20)$ & $0 / 15(0)$ & $2 / 15(13.3)$ \\
\hline \multicolumn{6}{|l|}{ CoNS } \\
\hline S. epidermidis & $22 / 40(55)$ & $0 / 40(0)$ & $4 / 40(10)$ & $0 / 40(0)$ & $0 / 40(0)$ \\
\hline S. Iugdunensis & $1 / 40(2.5)$ & $0 / 40(0)$ & $0 / 40(0)$ & $0 / 40(0)$ & $0 / 40(0)$ \\
\hline S. saprophyticus & $5 / 40(12.5)$ & $1 / 40(2.5)$ & $1 / 40(2.5)$ & $0 / 40(0)$ & $0 / 40(0)$ \\
\hline S. simulans & $2 / 40(5)$ & $0 / 40(0)$ & $0 / 40(0)$ & $0 / 40(0)$ & $0 / 40(0)$ \\
\hline S. xylosus & $2 / 40(5)$ & $0 / 40(0)$ & $0 / 40(0)$ & $0 / 40(0)$ & $0 / 40(0)$ \\
\hline Staphylococcus spp. & $4 / 40(10)$ & $1 / 40(2.5)$ & $1 / 40(2.5)$ & $0 / 40(0)$ & $0 / 40(0)$ \\
\hline Total & $36 / 40(90)$ & $2 / 40(5)$ & $6 / 40(15)$ & $0 / 40(0)$ & $0 / 40(0)$ \\
\hline
\end{tabular}

$\mathrm{N}=$ number of isolates; $\mathrm{T}=$ total of isolates; sea = gene fencoding enterotoxin $\mathrm{A} ; \mathrm{se} b=$ gene encoding enterotoxin $\mathrm{B} ;$ sec $=$ gene encoding enterotoxin $\mathrm{C}$; sed = gene encoding enterotoxin $\mathrm{D}$; tsst-1 = gene encoding toxic shock syndrome toxin 1 ; CPS = Coagulasepositive staphylococci; CoNS = Coagulase-negative staphylococci. 
Table 6 - Mono- and co-occurrence of toxin genes and toxin production in coagulase-positive staphylococci (CPS) and coagulasenegative staphylococci (CoNS) isolated from human milk in a Teaching Hospital from Sao Paulo State, Brazil.

\begin{tabular}{lcc}
\hline Gene/toxin & CPS & CoNS \\
\hline sea/SEA & $1 / 0$ & $29 / 1$ \\
seb/SEB & $0 / 0$ & $0 / 1$ \\
sec/SEC & $0 / 0$ & $1 / 0$ \\
sea + seb/SEA + SEB & $0 / 0$ & $2 / 0$ \\
sea + sec/SEA + SEC & $0 / 1$ & $5 / 0$ \\
sea + tsst-1/SEA + TSST-1 & $2 / 1$ & $0 / 0$ \\
sea + seb + sec/SEA + SEB + SEC & $1 / 0$ & $0 / 0$ \\
sea + seb + sec + tsst-1/SEA + SEB + SEC + TSST-1 & $0 / 0$ & $0 / 0$ \\
seb + sec/ SEB + SEC & $0 / 0$ & $0 / 0$
\end{tabular}

sea = gene encoding enterotoxin $A ; S E A=$ enterotoxin $A ; s e b=$ gene encoding enterotoxin $B ; S E B=$ enterotoxin $B ;$ sec = gene encoding enterotoxin $\mathrm{C} ; \mathrm{SEC}=$ enterotoxin $\mathrm{C} ;$ tsst-1 = gene encoding toxic shock syndrome toxin $1 ; \mathrm{TSST}-1$ = toxic shock syndrome toxin 1 .

matters of great impact on human health, as this food is essential for newborns in the first days of life, requiring a continuous vigilance of quality.

Acidity levels in Dornic degrees ( $\left.{ }^{\circ} \mathrm{D}\right)$ and the crematocrit of human breast milk are well-known main physicochemical parameters $^{26,27}$. Milk is a buffer system with a low concentration of free hydrogen ions. The acidity of human milk can be classified as original and developed. The term original results from the presence of its constituents (micelles of casein and mineral salts, among which phosphates and citrates stand out), whereas the developed is a consequence of the bacterial growth, from the primary and secondary microbiota, with the production of lactic acid ${ }^{26}$. In the current study, $95.4 \%$ of human milk samples had titratable acidity $<8.0^{\circ} \mathrm{D}$. Likewise, a large-scale comprehensive study with 4,204 human milk samples revealed $91.40 \%$ of samples with titratable acidity $<8.0^{\circ} \mathrm{D}^{27}$, values within the acceptable range, between $1.0-8.0^{\circ} \mathrm{D}$, recommended by the Brazilian human milk banks network ${ }^{17}$. However, it is reasonable to state that breast milk samples with titratable acidity $<8.0^{\circ} \mathrm{D}$ should be pasteurized to eliminate the pathogenic microorganisms, as opposed to milk samples with titratable acidity $\geq 8.0^{\circ} \mathrm{D}$ that should be discarded ${ }^{17,18}$. Increasing acidity at levels $\geq 7.0^{\circ} \mathrm{D}$ may be related to inadequate conditions of transport and storage of breast milk. The progressive increase of temperature stimulates fermentative action and enzyme production by bacteria present in milk, determining the degradation of triglycerides and increasing the concentrations of hydrogen ions, which lead to the reduction of $\mathrm{pH}$ and increase of the titratable acidity $^{28}$. These abnormalities result in a significant decrease in the quality of breast milk provided to newborns.

The caloric intake of breast milk sampled revealed variations of $11.29 \pm 1.54 \%$ for cream content, $7.33 \pm 0.65 \%$ for fat, and $1044.19 \pm 392.77 \mathrm{Kcal} / \mathrm{L}$ of total energy value.
The variation of fat content can be attributed to a number of factors, including the stage in the lactation cycle, genetic individuality, nursing mother's diet and differences between ethnic groups ${ }^{29}$. A study described changes in the mean percentage of milk fat collected manually at the beginning of the breastfeeding period $(2 \pm 1.9 \%)$, after five minutes $(9 \pm 2.8 \%), 10$ minutes $(11.4 \pm 4.6 \%)$, and at the end of breastfeeding $(14.3 \pm 3.8 \%)$, indicating that the phase of milk collection may influence the fat content ${ }^{30}$.

Breast milk can be a pathway for transmission of microorganisms to newborns if not handled under appropriate hygienic conditions ${ }^{10}$. The adoption of preventive measures reduces operational risks and secondary contamination from the environment, utensils, donors and healthcare professionals, ultimately providing safe and healthy food for infants and children ${ }^{1,17}$. Physicochemical parameters (acidity and crematocrit) of breast milk from the human milk bank in the teaching hospital studied here revealed within acceptable limits, and satisfactory conditions of milk collection from the nursing mothers.

Staphylococcus species are well-known bacteria that inhabit mucous membranes, conjunctiva and skin of humans and animals ${ }^{11}$. This group of bacteria has been isolated from human breast milk ${ }^{10}$. In the present study, $56.5 \%$ of bacterial isolated from breast milk belonged to the staphylococci group. These results are consistent with similar studies that have also reported the predominance of Staphylococcus species in human breast milk ${ }^{3,10,12}$.

Among the CoNS and CPS species identified in the current study, S. epidermidis $(71.4 \%)$ was the most prevalent, whereas $S$. aureus was responsible for only $4.5 \%$ of the total staphylococci species. In fact, S. epidermidis has been a frequent species isolated from human breast milk, probably because it contaminates milk through the maternal skin, a natural habitat of this pathogen ${ }^{31}$. 
Apart from staphylococci and streptococci groups, other miscellaneous microorganisms were identified in the breast milk sampled, including Klebsiella pneumoniae, Pseudomonas aeruginosa, Hafnia alvei, Klebsiella oxytoca, as well as Acinetobacter, Micrococcus genus and yeast. This finding reinforces the diversity of commensal and potentially pathogenic microorganisms that can contaminate breast milk ${ }^{3}$, and the importance of adopting best practices to limit the contamination of milk donors ${ }^{4,5}$.

Coliform bacteria are considered one of the main indicators of microbial contamination, as they are relatively simple pathogens to isolate using standardized and easyto-perform, economically viable and safe methods ${ }^{17,18}$. In the current study, $16.6 \%$ of the isolates belong to the Enterobacteriaceae family, including Klebsiella pneumoniae, Klebsiella oxytoca, Hafnia alvei, and Enterobacter genus. Interestingly, there was no isolation of $E$. coli in the current study, a fact that deserves attention because this microorganism is considered the main indicator of milk contamination ${ }^{17,18}$. Nevertheless, the presence of a complexity of microorganisms in the milk of the sampled nursing donors, particularly enterobacteria and staphylococci species, indicates the need for a continuous vigilance to prevent microbial contamination of breast milk, which may occur from a variety of sources, including human skin and/or gut, utensils used for milk collection and contaminants from the environment ${ }^{3,4}$.

No isolation of microorganisms was observed in $40 \%$ of the sampled human breast milk which is in line with other studies that have also reported the absence of isolation of bacteria in a variable number of samples from donors ${ }^{3,10}$. The high frequence of samples with no isolation of bacteria in the current study could be attributed to the best practices adopted in breast milk sampling to limit contamination ${ }^{4,5}$, as well as the fact that samples were collected from experienced donors, which have been frequently sampled over many years in the same teaching hospital.

The improper use of antimicrobials may increase the selective pressure on bacteria to become resistant ${ }^{21}$. In fact, the emergence of multidrug-resistant bacteria from humans and animals is a public health concern worldwide ${ }^{13}$. Here, amoxicillin/clavulanic acid (79.6\%), vancomycin (73.2\%), and cephalexin (71.3\%) were the most effective antimicrobials against all isolates. These drugs have been recommended to pregnant women due to their low residual excretion and few toxic adverse effects on neonates at therapeutic doses ${ }^{16}$. Nonetheless, there are few data related to the use of vancomycin in pregnant or lactating women and the occurrence of undesirable reactions, because the indication of this antimicrobial is restricted to cases of penicillin allergy, and multidrug bacterial resistance, mainly to erythromycin and clindamycin ${ }^{32}$. In turn, high resistance rates of isolates obtained from sampled donors were found to penicillin G (89.8\%), ampicillin (86\%) and oxacillin (75.2\%). In addition, multidrug-resistance for $\geq 3$ antimicrobials were observed in $66.2 \%$ of the isolates. The resistance profile of our isolates obtained from breast milk agrees with similar studies, where bacterial resistance has been reported predominantly to beta-lactam antibiotics, especially ampicillin and penicillin ${ }^{33,34}$. The high occurrence of bacterial resistance to the beta-lactam group may be attributed to the prophylactic use of pre- and postpartum antibiotics, caesarean procedures and self-medication of donors ${ }^{16}$, which may contribute to the increase of selective pressure on bacteria to become resistant for this group of drugs, reinforcing the importance of the rational use of antimicrobials during gestation and post-partum periods.

Delvotest $^{\mathrm{TM}}$ is an easy and fast commercial test standardized to identify the presence of microbial multiplication inhibiting substances in bovine milk. The presence of a set of antimicrobials such as beta-lactams, sulphonamides, tetracyclines, macrolides, aminoglycosides, lincosamides, amphenicols and dihydropyrimidine classes (groups) may be identified in milk ${ }^{22}$, because the improper use of antibiotics may increase the selective pressure on bacteria to become resistant, as well as residues of the drugs in milk may cause disorders in humans ${ }^{16}$. Among the 240 human milk samples, $85 \%$ revealed the presence of microbial multiplication inhibiting substances when tested by the commercial test (Delvotest ${ }^{\mathrm{TM}}$ ). This finding may be related to the preventive use of antibiotics to treat pre- and/or postpartum infections (e.g., cesarean procedures) ${ }^{34}$, by the improper use of drugs by nursing mothers ${ }^{16}$, or even secondary to the ingestion of products and derivatives from animal origin containing antimicrobial residues ${ }^{13}$. Nevertheless, the scarce information of antimicrobial residues or inhibitory substances in the breast milk of human banks indicates that similar studies should be conducted to investigate these substances in milk intended for neonatal consumption and their implications for infants. Furthermore, the test used in the current study is qualitative, standardized for bovines, and does not quantify the concentration of antimicrobials, a fact that may be considered a limitation of the study.

Phenotypic identification (disk diffusion method) has shown a variable association when compared to the detection of mecA gene in staphylococci isolated from milk samples $^{6,14,15}$. In this regard, a bacteriological study of 500 human milk samples from five human milk banks recovered 171 S. aureus, of which $57(11.4 \%)$ presented with methicillin-resistance and high resistance to oxacillin ${ }^{35}$. In the current study, among 240 milk samples, around 30\% 
of Staphylococcus isolates revealed resistance to cefoxitin and/or oxacillin and approximately $90 \%$ to penicillin using the disc diffusion test, whereas the $m e c A$ gene was detected in 53\% of the isolates based on the molecular method. In addition, among the 40 CoNS investigated here, $70 \%$ were resistant to cefoxitin and/or oxacillin, and $95 \%$ resistant to penicillin using the disc diffusion method, while the mecA gene was detected in $75 \%$ of CoNS. These results reinforce that, in some cases, it is possible to detect genes related to antimicrobial resistance without phenotypic expression ${ }^{36}$.

Staphylococcus species are well-known by the ability to produce toxins and cause food-related diseases ${ }^{6,11}$. The occurrence of puerperal mastitis, the colonization of the milk by commensal microorganisms, including staphylococci species, and the contamination of utensils during the collection or the storage of breast milk have been related to risk factors for the transmission of staphylococci species by milk to infants ${ }^{3,14}$. In fact, the presence of Staphylococcus species with toxigenic potential has been previously described in milk from healthy mothers ${ }^{6,14,31}$. A study involving bacteriological culture of breast milk of nine healthy mothers and ten presenting with clinical signs of mastitis revealed S. aureus in 13 milk samples. From these, eight revealed enterotoxins using the latex agglutination method, while SEA, SEB, SEC and TSST-1 were detected in three coagulase-positive staphylococci isolates, and SEA and SEB in five CoNS strains ${ }^{37}$. In the current study, among the 15 isolates of CPS, the sea, seb, sec, and tsst- 1 genes were found. The association of two or more genes was observed in $26.7 \%$ of the isolates. Two isolates produced staphylococcal toxins, one of which produced SEA and TSST-1, and another SEA and SEC. The detection of toxins in staphylococcal strains recovered from breast milk donors is an important concern, particularly because $s e c$ genes may resist to the heat treatment, i.e., pasteurization, and these potential reservoirs of staphylococcal toxin-producers may be transmitted to infants ${ }^{6}$.

CoNS are commensal inhabitants of skin and have been recognized as a less pathogenic group of bacteria ${ }^{13}$. This group of bacteria have been increasingly reported related to hospital and community-acquired infections, and their ability to form biofilms has been highlighted, as well as their relative resistance to antimicrobials ${ }^{38}$. However, the impact of staphylococci as commensal or potential pathogenic bacterial in breast milk is poorly understood. In this way, a study involving 54 Staphylococcus strains isolated from human milk revealed a high occurrence of CoNS, with predominance of S. epidermidis, S. warneri, S. haemolyticus and $S$. aureus ${ }^{37}$. Here, among the 40 CoNS isolated from breast human milk, $90 \%, 5 \%$, and $15 \%$ presented the sea, $s e b$ and sec genes, respectively, particularly S. epidermidis isolates. Moreover, one S. warneri produced SEA and another $S$. simulans produced SEB. Similar to CPS strains ${ }^{6}$, the presence of CoNS may be associated with skin or utensils contamination during the collection or the storage of breast milk, and detection of strains harboring sec genes related to toxin-production is an important matter because these genes confer resistance to heat.

A convenient milk sampling, no speciation by MALDI-TOF MS or other automatic system diagnosis method of bacterial species, and only around $45 \%$ of CoNS subjected to the phenotypic investigation of MRS may be considered limitations of the current study.

Apart from the well-known nutritional, immunological, and psychological benefits of breast-feeding to infants ${ }^{2}$, in the last decades, breastmilk has been recognized as a source of commensal and potentially probiotic microorganisms ${ }^{39}$ e.g., staphylococci, streptococci, lactic acid producing bacteria, which are able to colonize the neonatal gut in early life, considered a crucial stage of the neonatal period ${ }^{9}$. Immunomodulatory properties of some bacteria present in breast milk could reduce the occurrence of neonatal enteric, pulmonary and allergic disorders ${ }^{40}$. Thus, investigations focused on the microbiota of breast milk are important to contribute to the health status of neonates.

\section{CONCLUSION}

Overall, we identified the presence of microbial multiplication inhibiting substances, multidrug-resistant bacteria, Staphylococcus isolates harboring methicillinresistance genes, which are also toxin-producers, as well as a variety of other bacteria in the breast milk from a human bank in a teaching hospital in Brazil, highlighting the importance of best hygienic practices and the continuous vigilance of milk quality offered to infant consumption by human banks.

\section{ACKNOWLEDGMENTS}

The authors thank the Sao Paulo Research Foundation (FAPESP) for financial support (protocols $\mathrm{N}^{\circ} 2010 / 50823-5$ and 2008/53499-4), and the National Council for Scientific and Technological Development (CNPq), Brazil, for research productivity fellowships (PQ-1D) given to MGR.

\section{AUTHORS' CONTRIBUTIONS}

TS and MGR: conception, design, analysis, interpretation of data, and critical review; TS, PKS, AKS, MLRSC, LAZC, GHBL, and FJPL: collection of samples, laboratory assays, analysis and/or interpretation of data; AVS: statistical 
analysis; AKS, MGR, JGP, JPANP, LSAM, and RGM: article writing and/or critical review. All the authors approved the final version of the manuscript.

\section{CONFLICT OF INTERESTS}

The authors declare no conflict of interests.

\section{FUNDING}

This work was supported by Sao Paulo Research Foundation (FAPESP), Brazil (grants No 2008/53499-4 and 2010/50823-5).

\section{REFERENCES}

1. Brasil. Ministério da Saúde. Secretaria de Atenção à Saúde. Departamento de Atenção Básica. Saúde da criança: aleitamento materno e alimentação complementar. $2^{\mathrm{a}}$ ed. Brasília: Ministério da Saúde; 2016. [cited 2021 May 27]. Available from: https://bvsms.saude.gov.br/bvs/publicacoes/ aleitamento_materno_alimentacao_complementar_2edicao. pdf

2. Chang FY, Cheng SW, Wu TZ, Fang LJ. Characteristics of the first human milk bank in Taiwan. Pediatr Neonat. 2013;54:28-33.

3. Almutawif Y, Hartmann B, Lloyd M, Erber M, Geddes D. A retrospective audit of bacterial culture results of donated human milk in Perth, Western Australia. Early Hum Dev. 2017;105:16.

4. Froh EB, Vanderpool J, Spartz DL. Best practices to limit contamination of donor milk in a milk bank. J Obstet Gynecol Neonatal Nurs. 2018;47:547-55.

5. World Health Organisation. WHO recommendations for prevention and treatment of maternal peripartum infections. Geneva: WHO; 2015. [cited 2021 May 27]. Available from: https://www.who.int/reproductivehealth/publications/ maternal_perinatal_health/peripartum-infections-guidelines/ en/

6. Almeida JB, Carvalho SP, Almeida AL, Campos GB, Oliveira MV, Timenetsky J, et al. Detection, antibiotic resistance, and pathogenicity of staphylococci in samples from Brazilian human milk bank. Breastfeed Med. 2014;9:557-8.

7. Fernández L, Ruiz L, Jara J, Orgaz B, Rodríguez JM. Strategies for the preservation, restoration and modulation of the human milk microbiota: implications for human milk banks and neonatal intensive care units. Front Microbiol. 2018;9:2676.

8. Almutawif Y, Hartmann B, Lloyd M, Lai CT, Rea A, Geddes D. Staphylococcus aureus enterotoxin production in raw, holderpasteurized, and ultraviolet-C-treated donated human milk. Breastfeed Med. 2019;14:262-70.

9. Fernández L, Langa S, Martín V, Maldonado A, Jiménez E, Martín
$\mathrm{R}$, et al. The human milk microbiota: origin and potential roles in health and disease. Pharmacol Res. 2013;69:1-10.

10. Huang MS, Cheng CC, Tseng SY, Lin YL, Lo HM, Chen PW. Most commensally bacterial strains in human milk of healthy mothers display multiple antibiotic resistance. Microbiologyopen. 2019;8:e0618.

11. Quinn PJ, Markey BK, Leonard FC, Fitzpatrick ES, Fanning S, Hartigan. Veterinary microbiology and microbial disease. $2^{\text {nd }}$ ed. Oxford: Wiley-Blackwell; 2011.

12. Delgado S, Arroyo R, Jiménez E, Marín ML, del Campos R, Fernández L, et al. Staphylococcus epidermidis strains isolated from breast milk of women suffering infectious mastitis: potential virulence traits and resistance to antibiotics. BMC Microbiol. 2009;9:82.

13. World Health Organization. Antimicrobial resistance: global report on surveillance. Geneva: WHO; 2014. [cited 2021 May 27]. Available from: https://www.who.int/drugresistance/ documents/surveillancereport/en/

14. Almeida JB, Carvalho SP, Silva LS, Andrade YM, Chamon RC, Santos KR, et al. Molecular characterization of methicillinresistant and methicillin-sensitive Staphylococcus aureus isolates from human milk samples in Brazil. Braz J Microbiol. 2020;51:1813-17.

15. Williams MC, Dominguez SR, Prinzi A, Lee K, Parker SK. Reliability of mecA in predicting phenotypic susceptibilities of coagulase-negative staphylococci and Staphylococcus aureus. Open Forum Infect Dis. 2020;7:ofaa553.

16. Chaves RG, Lamounier JA, Cesar CC. Medicamentos e amamentação: atualização e revisão aplicadas a clínica materno-infantil. Rev Paul Pediatr. 2007;25:276-88.

17. Rede Brasileira de Bancos de Leite Humano. Leite humano ordenhado: determinação da acidez titulável - Método Dornic. Rio de janeiro: Fiocruz; 20011. [cited 2021 May 27]. Available from: https://rblh.fiocruz.br/sites/rblh.fiocruz.br/ files/usuario/79/nt_29.11_determinacao_acidez_lho.pdf

18. Brasil. Agência Nacional de Vigilância Sanitária. Banco de leite humano: funcionamento, prevenção e controle de riscos. Brasília: Anvisa; 2008. [cited 2021 May 27]. Available from: https://www.anvisa.gov.br/servicosaude/manuais/manual_ banco_leite.pdf

19. Cunha ML, Peresi E, Calsolari RA, Araujo Junior JP. Detection of enterotoxins genes in coagulase-negative staphylococci isolated from foods. Braz J Microbiol. 2006;37:70-4.

20. Clinical and Laboratory Standards Institute. Performance standards for antimicrobial susceptibility testing: CLSI supplement M100. 29 $9^{\text {th }}$ ed. Wayne: CLSI; 2019.

21. Magiorakos AP, Srinivasan A, Carey RB, Carmeli Y, Falagas ME, Giske CG, et al. Multidrug-resistant, extensively drug-resistant and pandrug-resistant bacteria: an international expert proposal for interim standard definitions for acquired resistance. Clin Microbiol Infect. 2012;18:268-81. 
22. DSM Food Specialties B.V. Delvotest ${ }^{\circledR}$ SP: test sensitivity or detection levels. [cited 2021 May 27]. Available from: https:// www.nmdrd.com/delvotest_technical_bulletin.pdf

23. Murakami K, Minamide K, Wada K, Nakamura E, Teraoka H, Watanabe S. Identification of methicillin-resistant strains of staphylococci by polymerase chain reaction. J Clin Microbiol. 1991;29:2240-4.

24. Hallander HO. Production of large quantities of entrotoxin B and other staphylococcal toxins on solid media. Acta Pathol Microbiol Scand. 1965;63:299-305.

25. Rose SA, Bankes P, Stringer MF. Detection of staphylococcal enterotoxins in dairy products by the reversed passive latex agglutination (SET-RPLA) kit. Intern J Food Microbiol. 1989;8:65-72.

26. Novak FR, Almeida JA, Guimarães V. Biossegurança em bancos de leite humano e postos de coleta de leite humano. Rio de Janeiro: Fiocruz; 2020. [cited 2021 May 27]. Available from: https://rblh.fiocruz.br/sites/rblh.fiocruz.br/files/usuario/80/6. nt15_20f_0.pdf

27. Cavalcante JL, Telles FJ, Peixoto MM, Rodrigues RC. Uso da acidez titulável no controle de qualidade do leite humano ordenhado. Food Sci Technol. 2005;25:103-8.

28. Moossavi S, Sepehri S, Robertson B, Bode L, Goruk S, Field CJ, et al. Composition and variation of the human milk microbiota are influenced by maternal and early-life factors. Cell Host Microbe. 2019;25:324-35.

29. Andreas NJ, Kampmann B, Le-Doare KM. Human breast milk: a review on its composition and bioactivity. Early Hum Dev. 2015;91:629-35.

30. Aksit S, Ozkayin N, Caglayan S. Effect of sucking characteristics on breast milk creamatocrit. Paediatr Perinat Epidemiol. 2002;16:355-60
31. Soeorg H, Metsvaht T, Eelmäe I, Treumuth S, Merila M, Ilmoja ML, et al. Coagulase-negative staphylococci in human milk from mothers of preterm compared with term neonates. J Hum Lact. 2017;33:329-40.

32. Wilhelm MP, Estes L. Symposium on antimicrobial agents: Part XII. Vancomycin. Mayo Clin Proc. 1999;74:928-35.

33. Chen PW, Tseng SY, Huang MS. Antibiotic susceptibility of commercial bacteria from human milk. Curr Microbiol. 2016;72:113-9.

34. Bonet M, Ota E, Chibueze CE, Oladapo OT. Routine antibiotic prophylaxis after normal vaginal birth for reducing maternal infectious morbidity. Cochrane Database Syst Rev. 2017;11:CD012137.

35. Novak FR, Almeida JA, Warnken MB, Ferreira-Carvalho BT, Hagler AN. Methicillin-resistant Staphylococcus aureus in human milk. Mem Inst Oswaldo Cruz. 2000;95:29-33.

36. Zhang Y, Wang X, Lejeune JT, Zervos M, Bhargava K. Comparison of phenotypic methods in predicting methicillin resistance in coagulase-negative Staphylococcus (CoNS) from animals. Res Vet Sci. 2011;90:23-5.

37. Pereira ML, Carmo LS, Santos EJ, Sellos IT, Bergdoll MS. Staphylococci in breast milk from women with and without mastitis. Rev Microbiol. 1995;26:117-20.

38. Becker K, Helmann C, Peters G. Coagulase-negative Staphylococcus. Clin Microbiol Rev. 2014;27:870-926.

39. Moossavi S, Miliku K, Sepehri S, Khafipour E, Azad MB. The prebiotic and probiotic properties of human milk: implications for infant immune development and pediatric asthma. Front Pediatr. 2018;6:197.

40. Bergman H, Rodríguez JM, Salminen S, Szajewska H. Probiotics in human milk and probiotic supplementation in infant nutrition: a workshop report. Br J Nutr. 2014;112:1119-28. 